\title{
Has COVID-19 Changed Crime? Crime Rates in the United States during the Pandemic
}

\author{
John H. Boman IV ${ }^{1}$ • Owen Gallupe ${ }^{2}$ \\ Received: 29 May 2020 / Accepted: 30 June 2020 / \\ Published online: 8 July 2020 \\ (C) Southern Criminal Justice Association 2020
}

\begin{abstract}
In response to the COVID-19 pandemic, state-level governments across the United States issued mandatory stay-at-home orders around the end of March 2020. Though intended to stop the spread of the COVID-19 virus, the lockdowns have had sweeping impacts on life in ways which were not originally planned. This study's purpose is to investigate the extent to which governmental responses to COVID-19 have impacted crime rates in the U.S. Compared to the pre-pandemic year of 2019, crime - as measured by calls for service to law enforcement - has decreased markedly. However, there are multiple indications that the crime drop is being driven by decreases in minor offenses which are typically committed in peer groups. At the same time, serious crimes which are generally not committed with co-offenders (namely homicide and intimate partner violence) have either remained constant or increased. As such, the crime drop appears to be hiding a very disturbing trend where homicides remain unchanged and intimate partner batteries are increasing. Since many offenders would presumably be committing less serious crimes in a non-pandemic world, we raise attention to the possibility that mandatory lockdown orders may have taken minor offenders and placed them into situations where there is rampant opportunity for intimate partner violence, serious batteries, and homicides. While crime in the U.S. appears to be down overall, this good news should not blind us to a troubling cooccurring reality - a reality that paints a dim picture of unintended consequences to public health and criminal justice finances as a result of COVID-19 lockdowns.
\end{abstract}

Keywords Crime rates · Coronavirus COVID-19 $\cdot$ Lockdown orders $\cdot$ Law enforcement Group-based offending $\cdot$ Intimate partner violence

John H. Boman, IV

jboman@bgsu.edu

1 John Boman, 229 Williams Hall, Bowling Green State University, Bowling Green,

OH 43403, USA

2 University of Waterloo, Waterloo, ON, Canada 


\section{Introduction}

Worldwide lockdowns and quarantines issued in response to the COVID-19 global pandemic have brought about a number of implications for everyday life. Unfortunately, most of the impacts of COVID-19 and the resulting lockdowns have been alarmingly negative - a gradually increasing death toll, job losses, unemployment, and a looming global financial crisis are among the most commonly reported issues worldwide. However, the pause to everyday life initiated by state governments in response to COVID-19 has resulted in scattered examples of positive changes as well. For instance, a notable drop in carbon-based emissions has reduced air pollution (Bauwens et al., 2020). Partially as a result of this, air quality across the globe has improved, resulting in a decline in the number of air-pollutant-instigated respiratory health problems (Dutheil, Baker, \& Navel, 2020).

Despite the abundance of negative implications of COVID-19, the air quality example demonstrates that there are a few unanticipated, but quite meaningful, benefits to everyday life that have been instigated by COVID-19. This raises attention to the key question explored by this research study: Has crime in the United States (U.S.) changed in response to COVID-19 stay-at-home orders? If so, has it decreased (resulting in an unexpected benefit to society) or increased (resulting in another harm to society)?

Focusing solely on crime in the U.S., this study's next section explores the first research question of whether crime has changed in response to COVID-19 and its lockdowns which have disrupted the American society and economy. On the whole, the short answer to this question is yes. Nearly all anecdotal evidence suggests that crime in the U.S. has indeed changed, and there are multiple indications that crime has decreased since the COVID-19 lockdowns began. At face value, this might seem like an unexpected benefit to society in a similar way to the improvements in air quality. However, the third section of this paper further dissects whether the reduction in crime is actually a benefit or a hindrance to American society. Specifically, we argue that the reduction of crime experienced in the U.S. actually masks a dramatic spike in several other types of crime that are tremendously harmful and costly to American society. The fourth and final section of this study offers concluding remarks with an eye towards forming responsible social policy in the wake of the COVID-19 pandemic.

\section{Has Crime Changed in the United States since the Pandemic Began?}

Nearly every major news source which has reported on this issue since COVID-19 lockdowns began have found a similar phenomenon: Crime is down across the United States. The most common metric of these reports is police calls for service (911 calls). Probably due to the fact that 911 calls are concrete events which are easily trackable over time, major news outlets like The Washington Post (Jackman, 2020), USA Today (Jacoby, Stucka, \& Phillips, 2020), and CNN (Waldrop, 2020) have all used this as the metric for determining that crime is down across the U.S.

In these major news sources, the extent to which crime has decreased since COVID19 lockdowns began varies dramatically. For example, The Washington Post (Jackman, 2020) reported decreases in calls for service in 29 of 30 jurisdictions including a $25 \%$ decline in Chicago and 20\% in Washington and Baltimore between March 16 and 
April 22, 2020 compared to the same period in 2019. USA Today reported that weekly calls for service dropped "at least" $12 \%$ between February 2 and March 28, 2020 across 30 police agencies (Jacoby et al., 2020). Although not providing exact numbers, CNN reports that calls for police service are down in New York City. Regarding the crime drop, New York City Police Commissioner Dermot Shea told CNN that "Crime has dropped off - off the face of the map, really" (Waldrop, 2020).

Despite the variability in the estimates to which crime is down, one finding seems relatively consistent: Crime has in fact decreased in the U.S. since states started moving towards lockdowns. While nearly all anecdotal evidence points towards crime being down, it is, however, important to realize that there are still many unknowns about the extent to which crime has decreased in the U.S. Three factors complicate this the most. First, to definitively determine that crime is down across the nation, national data - or at least nationally representative data - is needed. Second, calls for service are one, but not the only, metric for determining whether crime is down. Other metrics and measurement strategies are needed. Due to its wide acceptance as offering a realistic viewpoint on crime, we are especially in need of self-report data (see Krohn, Thornberry, Gibson, \& Baldwin, 2010 regarding the utility of self-report data). Third, most media sources focus on big cities. What is critically needed is a set of analyses on small- and medium-size cities and rural areas to determine if what is likely happening in big cities is happening in all areas of the U.S.

Due to the rapid-response nature of this special issue, the authors could neither speed up the natural process of data collections like the National Incident-Based Reporting System (NIBRS; see NIBRS, 2020) nor collect nationally representative data for this study. However, we did contact Police Chief David H. Tullis II of the Maumee Police Department in Maumee, Ohio - a city of 13,669 people (U.S. Census Bureau, 2019) to see how a smaller city was faring in the wake of COVID-19 lockdowns. Corroborating media reports on calls for service from elsewhere in the U.S., Chief Tullis's calls for service in Maumee are also down. Between January 1, 2019 and May 26, 2019, Maumee Police had exactly 3700 calls for service. During the same period (January 1 May 26) of 2020, they had received 2726 calls for service - a decrease of $26.3 \%$ in call volume. With little change in the city's population over this timeframe (see U.S. Census Bureau, 2019) and very few reasons to expect that confounding factors could prove this spurious, the presumable cause of this drop is the stay-at-home order that was issued by Ohio Governor DeWine in late March of 2020.

Despite nearly all anecdotal evidence pointing to crime in the U.S. being down, there is one scientific study that was recently released which focuses on how crime might have changed during COVID-19 (besides the ones in this thematic issue). Ashby (2020) performed a city-level analysis on over a dozen U.S. cities of various sizes and compared crime rates across six serious crimes - 1) serious assaults in public, 2) serious assaults in residences, 3) residential burglaries, 4) non-residential burglaries, 5) motor vehicle theft, and 6) stealing from cars. Using seasonal regression models which calculate the expected frequency of crime based on the prior year's crime trends (SARIMA models), Ashby's findings showed no consistent pattern as to whether crime had decreased, increased, or stayed the same during the pandemic. In fact, his most common finding was that of no change in crime rates pre- and post-COVID-19. When there were changes, they were random and seemed highly dependent on which particular city or county was being analyzed. 
Despite having a well-executed study that points to emerging evidence as to how COVID-19 is impacting crime rates, Ashby (2020) faced the same limitations all criminologists currently do about how crime is fluctuating in response to COVID-19: A lack of sufficient data. The most widely available data source right now on judging how COVID-19 has impacted crime comes from publicly available police data. The limitations of official police data are well documented. Due to police simply not knowing about offenses due to under/non-reporting of crime (MacDonald, 2002), police data do a very poor job at capturing one of Ashby's variables - serious assaults which occur within the home. This variable is capturing something that is similar to, but not synonymous with, intimate partner violence (IPV; see Ashby's discussion on $\mathrm{p}$. 14). Evidence dating back over 20 years demonstrates that IPV is most frequently not reported to the police (e.g., Bachman \& Saltzman, 1995). While estimates vary, only about half of IPV incidents result in a 911 call (Reaves, 2017). And due to the frequent ambiguity of 911 calls (see New Jersey Division of Criminal Justice, 2003) and the common situation where law enforcement officers cannot substantiate a domestic battery occurring (only about $40 \%$ of cases result in arrest; Reaves, 2017), IPV is certainly an underestimated variable with police data (cf. Bachman \& Saltzman, 1995; Reaves, 2017; also see Gracia, 2004). Self-report data on perpetration or victimization data would be highly preferential to capture IPV (see Straus \& Gelles, 1990).

\section{Searching for Meaning: The Utility of the COVID-19 Crime Drop}

Nearly all evidence on calls for service nationwide demonstrate that crime is down, but Ashby (2020) has just found that serious crimes are largely unchanged and highly location dependent. What is the reason for this difference? The most likely explanation lies in the types of crimes Ashby (2020) investigated - most of the crimes he was able to capture are felonies and index crimes (hence the reason why they were in publicly available police data). The severity of these crimes may position them to behave differently than more common, 'everyday-type' misdemeanors. This raises attention to Warr's (2002) distinction between what he calls 'groupy' and 'non-groupy' crimes. Groupy crimes are mostly minor crimes that are committed in groups generally consisting of younger offenders. The purpose of these crimes is to alleviate boredom and gain social status and social capital. Examples of groupy crimes include vandalism, trespassing, and substance use. On the other hand, non-groupy crimes are offenses that tend to be committed by individuals acting alone rather than people in groups. Some examples of non-groupy crimes include IPV, serious theft, serious battery, and homicide. Notably, Ashby's crimes were nearly all non-groupy crimes and are serious offenses which are typically committed alone and not in the presence of others in peer networks or groups.

During COVID-19 lockdowns, peer dynamics have clearly been altered due to stayat-home orders and social distancing requirements. We argue that these disruptions to established social patterns are the driving force behind the reduction in offending over the course of the pandemic. Without access to peer groups, the context in which much criminal behavior occurs is removed (Osgood, Wilson, O’Malley, Bachman, \& Johnston, 1996). With no school to attend, students cannot congregate afterwards. This is important since a typical day would see a 'spike' in crime after school lets out when youthful offenders have little to no supervision (see Gottfredson, Gottfredson, \& 
Weisman, 2001). While the after-school crime spike is a time and context in which substantial amounts of minor offending typically occurs, it cannot occur if adolescents are not attending school.

During the stay-at-home order, the opportunity for underage drinking with friends and the minor offending that often accompanies it - also largely disappears without the option of attending parties. Since groupy offenses constitute the majority of criminal acts, ${ }^{1}$ it is likely that the NIBRS data will eventually show that they carried the bulk of the crime reduction following state government responses to COVID-19. Supporting this anecdotally, Chief Tullis noted that since the start of mandatory lockdowns in Ohio, his officers are seeing very few peer groups coming into conflict with the law. Underage drinking is nearly non-existent since nobody is going out in groups. In fact, nearly everyone getting arrested in his department's jurisdiction are acting alone. Due to the commonality of arresting people who are committing crime with co-offenders, Chief Tullis stressed that the lockdowns issued in response to COVID-19 have represented a dramatic shift in policing.

While physical distancing requirements and lockdowns have clearly impacted group-based offending, they are unlikely to have any bearing on criminal acts that generally occur in situations when peer groups are not present. In other words, lockdown orders are unlikely to impact non-groupy crimes. In this case, it would make sense that serious crimes like homicide and IPV would not change during a lockdown order, especially in a climate charged with the mental stress and anxiety associated with forced lockdowns.

If this were true, we would expect to see relative stability in homicide figures from 2020 compared to 2019. Using data from two cities which have recently been homicide hotspots - Chicago and Philadelphia - there does not appear to be any noticeable changes in homicides compared to this point in 2019. Between January 1 and May 28, 2020, Chicago had 191 homicides. During the same time period of 2019, Chicago had 192 homicides (see Chicago Tribune, 2020). Between January 1 and May 29, 2020, Philadelphia experienced 151 homicides. During this same time frame in 2019, Pennsylvania's largest city had experienced 131 homicides (see Philadelphia Police, 2020). Accordingly, these figures suggest that COVID-19 lockdowns do not appear to have had any effect whatsoever on Chicago homicides and may have contributed to a 15\% increase in homicides in Philadelphia in 2020 compared to 2019.

While valid data are much more difficult to come by, there is also anecdotal evidence that IPV may have worsened as a result of the lockdowns issued in response to COVID-19. Lockdowns have forced those who cohabit to remain in close proximity with each other and thereby have increased the opportunity for domestic provocation and intimate partner altercations. Furthermore, there are abundant opportunities for access to victims and limited options for victims since the possibility of escape and the likelihood of intervention by social service agencies - many which are closed - is no longer a viable option. In effect, stay-at-home orders can exacerbate the situational dynamics which produce individual-based offenses like IPV. To this point, data from the Maumee Police Department demonstrate that there has in fact been an increase in substantiated IPV incidents in 2020 (73 incidents; data to May 26, 2020) compared to

\footnotetext{
${ }^{1}$ For example, in 2018, the U.S. experienced over 1.1 million reported shoplifting incidents compared to a combined total of 437,655 murders, rapes, and robberies (see FBI, 2020).
} 
the same point in the year of 2019 (55 incidents). This 33\% increase does not include 'domestic arguments,' a term used by the department when there is a domestic-related call for service but in which IPV cannot be substantiated enough to warrant an arrest. Unfortunately, domestic argument calls have more than doubled (2.5x higher) during the COVID-19 lockdowns compared to the same time period in the pre-COVID year of 2019. The mandatory stay-at-home orders coupled with job loss and high alcohol consumption rates have created what Chief Tullis termed a "toxic cocktail" in a semi-structured, qualitative interview with the lead author. We encourage the reader to refer to several other studies in this special issue of the American Journal of Criminal Justice that specifically focus on domestic battery and IPV.

In sum, minor offenses - many of which occur in peer groups - are quite common in the U.S. Individualistic behaviors like IPV and homicide are rarer but are far more detrimental to society. Since there are so many more minor, group-based offenses compared to serious, non-group-based crimes, changes to the social order that produce reductions in minor offending will end up causing the overall crime rate to drop even in the presence of increases in more serious crime. While the magnitude of these changes will become clearer over time, the key question arises: Should we consider the crime drop in the United States to be an unanticipated benefit of the COVID-19 lockdowns? Just as reductions in carbon emissions are desirable but can overshadow the suffering of employees of the oil and gas industry, we might want to consider the nuance contained within the COVID-19 crime drop before celebrating. Within the context of the overall reduction in the crime rate during mandatory COVID-19 lockdowns, is it a social benefit if we replace every two (or three, or four, etc.) shoplifting incidents with one extra IPV-related crime? We believe this is not a desirable tradeoff and thereby would caution against celebrating the reduction in crime that the U.S. is currently experiencing.

\section{Conclusions}

In the wake of official responses to COVID-19, mass lockdowns, and stay-at-home orders issued by state governments throughout the U.S., there has been a decline in crime. However, we have argued that the decrease in crime is probably instigated due to a drop in more minor crimes that tend to be committed with groups of peers. Since about half of crime in the U.S. is committed by young offenders (people who often tend to offend in groups; see Warr, 2002), the reduction in the sheer volume of these common offenses has been the primary driving factor behind why crimes in the U.S. appear to be decreasing during COVID-induced lockdowns. Instead, crimes that are committed without co-offenders - IPV, serious battery, and homicide - have either remained the same or increased. As such, evidence suggests that the fundamental reason why crime is down across the U.S. is probably because government-mandated lockdowns have temporarily removed the peer group as a viable means of providing available offenders.

This realization questions the meaningfulness of the decrease in crime in the wake of COVID-19. If we are correct, the decline in crime is deceiving at best and, even more problematically, harmful at worst. In Chicago and Philadelphia, two of the current hotspots of homicide, murders have either not changed or have increased during the 
COVID-19 lockdowns. And if IPV is climbing due to mandated home confinements, then we have essentially shifted available offenders - many of whom would presumably be committing minor offenses in groups that carry little impact to society - into settings where there is the opportunity to commit more serious crimes that have direct and noticeable impacts on human physical health, mental health, and overall longevity. In other words, the government-mandated lockdowns may have taken the opportunity to commit vandalism away and instead provided available offenders with the ability to commit IPV and homicide instead.

The potential costs of this accidental reality go far beyond the human condition. In terms of financial costs incurred by society, IPV is often considered to be one of the most expensive crimes that is committed (Peterson et al., 2018). Survivors of IPV often require extensive mental health treatment and counseling, need rehousing, experience dramatic work and wage loss, and utilize limited social service resources (Lyon, Lane, \& Menard, 2008). Likewise, homicide is another extremely expensive crime (Wickramasekera, Wright, Elsey, Murray, \& Tubeuf, 2015). In addition to extreme court costs associated with prosecution (Hunt, Anderson, \& Saunders, 2017), family members, loved ones, and dependents also require extensive mental health counseling and experience job loss and mental health problems as well (see Mastrocinque \& Cerceo, 2019). As such, there is a realistic possibility that the lockdown-type response to COVID-19 that has been seen across the U.S. has reduced petty crimes while increasing IPV and failing to impact homicide. In other words, the federal and state governments may have unknowingly reduced crimes that have little impact to society while doing nothing to help - or, even worse, increasing crimes that carry the highest costs to society.

While crime has decreased across the U.S., this study has questioned the appropriateness of celebrating this decrease. While crime overall is down, the reason it is down is likely due to a drop in only minor crimes which are largely committed by people in peer groups. By issuing lockdowns in the wake of COVID-19, deviant peer groups - groups of relatively young people who commit minor crimes for social capital - were effectively eliminated during the duration of the lockdown. The after-school crime spike (see Gottfredson et al., 2001) cannot happen if there is no school. Our study meshes with Chief Tullis's fears and Ashby's (2020) most common finding, which was that serious crime in the U.S. has not changed or is increasing in the wake of COVID-19. If crime in place and space decreases, it is typically seen as a good thing. However, due to the potential that COVID-19 lockdowns may have shifted minor offenders into having new opportunities to commit serious crimes, we urge caution against a 'catch-all' interpretation that the crime drop during the COVID-19 lockdown has been beneficial to society.

Acknowledgements The authors would like to graciously thank Police Chief David H. Tullis II of the Maumee Police Department (Ohio) for sharing his and his department's experiences with the authors.

Funding Information This research was supported in part by the Center for Family and Demographic Research, Bowling Green State University, which has core funding from the Eunice Kennedy Shriver National Institute of Child Health and Human Development (P2CHD050959).

\section{Compliance with Ethical Standards}

Conflicts of Interest / Competing Interests None. 


\section{References}

Ashby, M. P. J. (2020). Initial evidence on the relationship between the coronavirus pandemic and crime in the United States. Crime Science, 9(6), 1-16.

Bachman, R., \& Saltzman, L. (1995). Bureau of Justice Statistics Special Report: Violence against women: Estimates from the redesigned survey (NCJ-154348). Washington, DC: US Department of Justice, Bureau of Justice Statistics.

Bauwens, M., Compernolle, S., Stavrakou, T., Müller, J. F., van Gent, J., Eskes, H., et al. (2020). Impact of coronavirus outbreak on NO2 pollution assessed using TROPOMI and OMI observations. Geophysical Research Letters, online first.

Chicago Tribune. (2020, May 28). Tracking Chicago homicide victims. Available at https://www. chicagotribune.com/news/breaking/ct-chicago-homicides-data-tracker-htmlstory.html.

Dutheil, F., Baker, J. S., \& Navel, V. (2020). COVID-19 as a factor influencing air pollution? Environmental Pollution, online first.

Federal Bureau of Investigation (FBI). (2020). Crime in the United States, 2018. Available at https://ucr.fbi. gov/crime-in-the-u.s/2018/crime-in-the-u.s.-2018/topic-pages/tables/table-7.

Gottfredson, D. C., Gottfredson, G. D., \& Weisman, S. A. (2001). The timing of delinquent behavior and its implications for after-school programs. Criminology \& Public Policy, 1(1), 61-86.

Gracia, E. (2004). Unreported cases of domestic violence against women: Towards an epidemiology of social silence, tolerance, and inhibition. Journal of Epidemiology \& Community Health, 58, 536-537.

Hunt, P., Anderson, J., \& Saunders, J. (2017). The price of justice: New national and state-level estimates of the judicial and legal costs of crime to taxpayers. American Journal of Criminal Justice, 42(2), 231-254.

Jackman, T. (2020, May 19). Amid pandemic, crime dropped in many U.S. cities, but not all. Retrieved May 28, 2020, from https://www.washingtonpost.com/crime-law/2020/05/19/amid-pandemic-crimedropped-many-us-cities-not-all/

Jacoby, K., Stucka, M., \& Phillips, K. (2020, April 16). Crime rates plummet amid the coronavirus pandemic, but not everyone is safer in their home. Retrieved May 28, 2020, from https://www.usatoday. com/story/news/investigations/2020/04/04/coronavirus-crime-rates-drop-and-domestic-violencespikes/2939120001/

Krohn, M. D., Thornberry, T. P., Gibson, C. L., \& Baldwin, J. M. (2010). The development and impact of self-report measures of crime and delinquency. Journal of Quantitative Criminology, 26(4), 509-525.

Lyon, E., Lane, S., Menard, A. (2008). Meeting survivors' needs: A multi-state study of domestic violence shelter experiences. National Institute of Justice, Final Grant Report. Available at https://www.ncjrs. gov/pdffiles1/nij/grants/225025.pdf.

MacDonald, Z. (2002). Official crime statistics: Heir use and interpretation. The Economic Journal, 112(477), F85-F106.

Mastrocinque, J. M., \& Cerceo, E. A. (2019). Understanding the needs and experiences of families and friends of homicide victims: A research-to-practice fellowship project. Center for Victim Research, Rowan University. Available at https://ncvc.dspacedirect.org/bitstream/item/1360/R2P\%20 Fellowships\%202018_Understanding\%20the \%20Needs\%20and\%20Experiences \%20of\%20 Families $\% 20$ and $\% 20$ Friends $\% 20 \mathrm{of} \% 20$ Homicide $\% 20$ Victims.pdf?sequence $=1$.

National Incident-Based Reporting System (NIBRS). (2020). Retrieved May 28, 2020 from https://www.fbi. gov/services/cjis/ucr/nibrs.

New Jersey Division of Criminal Justice. (2003). Handling a domestic violence call: In-service training for police dispatchers. Available at https://www.njpdresources.org/dom-violence/dv-dispatcher-instr.pdf.

Osgood, D. W., Wilson, J. K., O’Malley, P. M., Bachman, J. G., \& Johnston, L. D. (1996). Routine activities and individual deviant behavior. American Sociological Review, 61(4), 635-655.

Peterson, C., Kearns, M. C., McIntosh, W. L., Estefan, L. F., Nicolaidis, C., McCollister, K. E., \& Florence, C. (2018). Lifetime economic burden of intimate partner violence among US adults. American Journal of Preventive Medicine, 55(4), 433-444.

Philadelphia Police. (2020, May 29). Crime maps \& stats: Homicide. Available at https://www.phillypolice. com/crime-maps-stats/.

Reaves, B. A. (2017). Police response to domestic violence, 2006-2015 (NCJ 250231). Bureau of Justice Statistics. Available at https://www.bjs.gov/content/pub/pdf/prdv0615.pdf.

Straus, M. A., \& Gelles, R. J. (1990). How violent are American families? Estimates from the national family violence resurvey and other studies. Physical Violence in American Families, 8, 95-112.

U.S. Census Bureau. (2019). QuickFacts: Maumee, Ohio. Available at https://www.census. gov/quickfacts/maumeecityohio. 
Waldrop, T. (2020, April 1). Coronavirus has police everywhere scrambling to respond as their forces are reduced. Retrieved May 28, 2020 from https:/www.cnn.com/2020/04/01/us/police-coronavirus/index. html.

Warr, M. (2002). Companions in crime. New York, NY: Cambridge University Press.

Wickramasekera, N., Wright, J., Elsey, H., Murray, J., \& Tubeuf, S. (2015). Cost of crime: A systematic review. Journal of Criminal Justice, 43(3), 218-228.

Publisher's Note Springer Nature remains neutral with regard to jurisdictional claims in published maps and institutional affiliations.

John Boman is an Associate Professor in the Department of Sociology at Bowling Green State University in Bowling Green, Ohio. As a criminologist, his research is primarily quantitative and focuses mainly on social relationships, peer networks, substance use, and measurement and construct validation. Some of his recent work has been published in Criminology, the Journal of Research in Crime and Delinquency, Justice Quarterly, and Criminology \& Public Policy.

Owen Gallupe is an Associate Professor in the Department of Sociology and Legal Studies at the University of Waterloo. His research focuses mainly on peer influence, social networks, and offending. His recent work has been published in venues such as Journal of Research in Crime and Delinquency, Journal of Quantitative Criminology, and Justice Quarterly. 